\title{
ACUTE CONFUSIONAL STATE IN SLE. COEXISTING SLE AND NON-SLE ETIOLOGY
}

Daniela Gomes Chicre Oliveira ${ }^{1, \star}$, Marina Ferreira Simões ${ }^{1}$, Carlos Eduardo Garcez Teixeira ${ }^{1}$, Isabela Tambelli Pires Cardoso ${ }^{1}$, Patrick Fontes Rodrigues ${ }^{1}$, Luiz Pierre Huning ${ }^{1}$, Vitor Corsaletti Abreu ${ }^{1}$, Marcondes Cavalcante França Junior ${ }^{1}$, Fabiano Reis ${ }^{1}$, Lilian Tereza Costallat ${ }^{1}$, Simone Appenzeller ${ }^{1}$

1.Universidade Estadual de Campinas, Campinas (SP), Brazil.

*Corresponding author: danielachicre@gmail.com

\section{BACKGROUND}

Systemic lupus erythematosus (SLE) is an autoimmune, inflammatory, chronic disease with multisystem impairment, which leads to heterogeneous symptoms that can mimic miscellaneous illnesses leading to a challenging diagnosis.

\section{CASE REPORT}

A 46-year-old male was admitted for diagnostic investigation and treatment due to mental confusion. During the previous year, he presented progressive memory loss, episodes of disorientation and inability to work associated with hair loss, nonpruritic cutaneous erythematosus lesions in malar and sun-exposed areas, muscular weakness, myalgia, intermittent fever and weight loss. The patient had no comorbidities and a negative social history of smoking, alcoholism and illegal drug use. In physical examination, he was pale, dehydrated, emaciated, afebrile, with brownish skin lesions in malar region and upper limbs, alopecia and with diminished proximal muscular strength (grade 3) in lower limbs. Blood tests showed hyponatremia ( $124 \mathrm{mmol} / \mathrm{L}$ ), normochromic and normocytic anemia with normal leukogram, C-reactive protein of $124 \mathrm{mg} / \mathrm{L}$ and erythrocyte sedimentation rate of $36 \mathrm{~mm} / \mathrm{h}$. Cranial tomography demonstrated focal hypodensities and cerebrospinal fluid analysis with increased protein ( $123 \mathrm{mg} / \mathrm{dL})$, leukocytosis $\left(14 / \mathrm{mm}^{3}\right)$, normal glucose and negative cultures, suggestive of aseptic meningitis. Brain magnetic resonance demonstrated hippocampal atrophy, diffuse cortical-subcortical oval lesions, with flair hyperintensities, without restriction to diffusion, enhancement on postcontrast images or meningeal changes. Chest and abdomen tomography evidenced diffuse lymph node enlargement. Infectious, oncologic and endocrinological diseases were ruled out. Cutaneous biopsy showed IgA, IgM, IgG, C'3 and C1q deposit in basement membrane, annexes and blood vessels walls. Further evaluation found antinuclear antibody (ANA) positive $1 / 640$ nuclear large speckled pattern, reduced C3/C4 levels, positive anti-Sm and negative anti-DNA. SLE diagnosis was made and prednisone $1 \mathrm{mg} / \mathrm{kg}$, hydroxychloroquine $5 \mathrm{mg} / \mathrm{kg}$ and mycophenolate $1440 \mathrm{mg} / \mathrm{day}$ were started with improvement of general condition, remission of cutaneous lesions and aseptic meningitis. The patient maintained mental confusion which was associated with hyponatremia secondary to syndrome of inappropriate antidiuretic hormone secretion (SIADH), showing signs of improvement after water restriction and use of diuretics.

\section{CONCLUSION}

Neuropsychiatric lupus is a rare and challenging illness. The symptoms can mimic several conditions and the diagnosis and early treatment are essential to prevent long-term damage.

\section{KEYWORDS}

Lupus, Neuropsychiatric, SIADH, Aseptic, Meningitis. 